\title{
Theoretical Study on the Grafting Reaction of Maleimide Containing 2-Hydroxy-Benzophenone Onto Polyethylene
}

hui Zhang ( $\square$ hust_zhanghui11@hotmail.com )

Harbin University of Science and Technology

Chi Deng

Harbin University of Science and Technology

Xia Du

Harbin University of Science and Technology

Yan Shang

Harbin University of Science and Technology

Hong Zhao

Harbin University of Science and Technology

Xuan Wang

Harbin University of Science and Technology

Baozhong Han

Harbin University of Science and Technology

Zesheng Li

Harbin University of Science and Technology

\section{Research Article}

Keywords: Cross-linked Polyethylene, Maleimide, Benzophenone, Transition states

Posted Date: May 10th, 2021

DOI: https://doi.org/10.21203/rs.3.rs-478525/v1

License: (c) (1) This work is licensed under a Creative Commons Attribution 4.0 International License.

Read Full License

Version of Record: A version of this preprint was published at Journal of Molecular Modeling on August 20th, 2021. See the published version at https://doi.org/10.1007/s00894-021-04874-2. 
2 2-Hydroxy-Benzophenone onto Polyethylene

3 Hui Zhang ${ }^{\mathrm{a}, 1}$, Chi Deng ${ }^{\mathrm{a}}$, Xia Du ${ }^{\mathrm{a}}$, Yan Shang ${ }^{\mathrm{a}}$, Hong Zhao ${ }^{\mathrm{a}, 2}$, Xuan Wang ${ }^{\mathrm{a}}$,

4 Baozhong Han ${ }^{\mathrm{a}, \mathrm{b}, 3}$, Zesheng $\mathrm{Li}^{\mathrm{c}}$

$5 \quad{ }^{a}$ Key Laboratory of Engineering Dielectrics and Its Application of Ministry of Education \& School

6 of Material Science \& Engineering, Harbin University of Science and Technology, Harbin $7 \quad$ 150080, P.R. China;

$8 \quad$ b Shanghai Qifan Cable Co., Ltd., Shanghai 200008, P.R. China

$9{ }^{\mathrm{c}}$ Key Laboratory of Cluster Science of Ministry of Education \& School of Chemistry, Beijing 10 Institute of Technology, Beijing 100081, P.R. China;

Abstract: A theoretical study on the multi-channel hydrogen addition of maleimide containing 2-hydroxy-benzophenone onto polyethylene in Ultra-Violet (UV) radiation cross-linking process was carried out using density functional theory (DFT) method at the B3LYP/6-311+G(d,p) level. The energetic information and the minimum energy path (MEP) are calculated of nine reaction channels. The electrophilic addition reactions at two positions in the target molecule (maleimide containing 2-hydroxy-benzophenone) were investigated, where are on the $\mathrm{C}$ atom of $\mathrm{C}=\mathrm{C}$ groups and on the $\mathrm{O}$ atom of $\mathrm{C}=\mathrm{O}$ groups. Frontier MOs and $\mathrm{NBO}$ charge population of the target molecule have been analyzed in detail. As a result, the reaction site of $\mathrm{C}$ in $\mathrm{C}=\mathrm{C}$ group is more active than the site of $\mathrm{O}$ in $\mathrm{C}=\mathrm{O}$ groups. The target molecule can be used as a multi-functional additive candidate. The predicted mechanism may provide a theoretical basis for the real application of XLPE high voltage insulation cables.

Keywords: Cross-linked Polyethylene; Maleimide; Benzophenone; Transition states

${ }^{1}$ Corresponding author e-mail: hust_zhanghui11@hotmail.com

${ }^{2}$ Corresponding author e-mail: hongzhao@hrbust.edu.cn

${ }^{3}$ Corresponding author e-mail: hbzhlj@163.com 


\section{Introduction}

Cross-linked polyethylene (XLPE) insulation cables have broad application prospects in high voltage and ultra-high voltage fields due to the superiority of their electrical performance [1]. The insulation material is one of the most important issues for restricting the fast development of polymeric high voltage direct current (HVDC) cables in the near future. The electrical treeing and the space charge accumulation leads to decreasing of service behavior in-service XLPE cables [2-5]. Hence, voltage stabilizer and space charge inhibitor are needed to increase the electric breakdown strength and inhibit space charge accumulation in the polyethylene (PE) insulation materials. Voltage stabilizers can effectively improve the electrical treeing resistance, which usually have polycyclic aromatic hydrocarbons structure [6-11]. Our group proposes a guiding criterion using the electron affinity and the reaction potential barrier heights to identify high efficiency of the voltage stabilizers [5-7]. And it is reported that polar molecules (such as maleic anhydride) can be grafted to the polymer chains with the aim of inducing deep traps and reducing the accumulation of space charge $[12,13]$. Our group also proposes a guiding criterion using the reaction potential barrier heights to identify high efficiency of the space charge inhibitor [14-15].

Compared with the traditional dicumyl peroxide (DCP) crosslinking technology, Ultra-Violet (UV) radiation crosslinking technology has become a candidate because of its advantages such as fast processing speed, small radiation area, energy saving and insensitive to heat. And theoretical studies [16-17] also show that the reaction energy barrier of hydrogen abstraction on the PE chain by benzophenone (BP) is 0.17 $\mathrm{eV}$ in the $\mathrm{UV}$ radiation cross-linking process, which is $0.08 \mathrm{eV}$ lower than $0.25 \mathrm{eV}$ for the hydrogen abstraction on the PE chain by the cumyl peroxide $(\mathrm{CP})$ radical in DCP 
cross-linking process. This indicates that UV radiation cross-linking process has the advantage of replacing traditional DCP process for XLPE production.

Recently, Kim's group [18] reported the reaction conditions and photo-stabilization effects of the synthesized novel UV absorber (abbreviated as AB, a benzoic acid derivative containing maleimide group and 2-hydroxy-benzophenone group). As an effective light stabilizer, UV absorber is widely used to assimilate UV light with short wavelength (200-400 nm) and convert it into harmless form. This give us an inspiration, can the $\mathbf{A B}$ be used as a multi-functional additive to improve the voltage stabilization and space charge inhibition property of insulation materials? Molecular structure of the $\mathbf{A B}$ is presented in Fig.1. The name and abbreviation of the studied molecules are listed in Table 1. We expect the carbonyl group or benzene in $\mathbf{A B}$ molecule to act as deep traps to inhibit space charge and meanwhile it can be used as a voltage stabilizer to improve electrical tree resistance capability. The addition of the multi-functional $\mathbf{A B}$ in system would decrease the amount of additive to reduce the introduction of chemical impurities, the electronic conductivity of the materials will reduce.

In this paper, 4-methylheptane (Pe) was selected as model molecule of $\mathrm{PE}$, we further clarify and verify the possibility of the $\mathbf{A B}$ used as a potential multi-functional additive with the capability of capturing electrons. There are three issues need to be solved. (1) Whether the $\mathbf{A B}$ can be sensitized to triplet state with the help of initiator BP? (2) Which sites of addition reaction on the $\mathbf{A B}$ is more reactive, double bond addition or carbonyl hydrogen addition? (3) Which reaction channel should be the dominant one among four hydrogen addition sites in $\mathbf{A B}$ molecule?

Clarifying the reaction mechanism is beneficial to optimize the crosslinking process of UV radiation and promote the development of high voltage cable insulation 
materials.

\section{Computational Methods}

In this work, the geometry optimizations and frequency calculations of all the stationary points on the ground state $\mathrm{S}_{0}$ or the triplet state $\mathrm{T}_{1}$ were carried out by DFT method [19] at the B3LYP [20-23] functional level with the 6-311+G(d,p) basis set. The minimum energy path (MEP) is calculated at the same level and obtained by the intrinsic reaction coordinate (IRC) theory. The gradient step is 0.05 (amu $)^{1 / 2}$ Bohr. Based on these electronic structure calculations, we obtain the values of $E_{\mathrm{g}}, \operatorname{IP}(a)$ and EA(a), respectively. $E_{\mathrm{g}}$ refers to the energy gaps between the highest occupied molecular orbital (HOMO) and the lowest unoccupied molecular orbital (LUMO), $\operatorname{IP}(a)$ refers to the adiabatic ionization potentials and $\mathrm{EA}(a)$ refers to the adiabatic electron affinities. Based on the optimized geometries, we calculate the lowest triplet excitation energies $\left(T_{1}\right)$ of the studied molecules by the time-dependent density functional theory (TDDFT) method [24,25]. The natural charge population was analyzed by the natural bond orbital (NBO) method [26]. All the electronic structure calculations were performed by the GAUSSIAN09 program package [27].

\section{Results and Discussion}

The calculated lowest triplet excitation energies $\left(\mathrm{T}_{1}\right)$ of $\mathbf{A B}(0.10 \mathrm{eV})$ in this work is much lower than that of the photo-initiator $\mathrm{BP}(0.73 \mathrm{eV})$ [15] at the B3LYP/6-311+G(d,p) level by the TDDFT method [24,25]. In the process of UV radiation, $\mathrm{BP}$ will be excited from $\mathrm{S}_{0}$ to its singlet excited state $\mathrm{S}_{1}\left(\mathrm{n}, \pi^{*}\right)$ and after to its triplet excited state $\mathrm{T}_{1}\left(\mathrm{n}, \pi^{*}\right)$ through inter system crossing (ISC). According to the sensitization rule, $\mathbf{A B}$ molecule will be sensitized to its $\mathrm{T}_{1}$ state by $\mathrm{BP}$ because the excitation energies of $T_{1}$ state is $0.63 \mathrm{eV}$ lower than that of $\mathrm{BP}$. That is to say, the $\mathrm{T}_{1}$ state $B p$ quenches by the $S_{0}$ state $\mathbf{A B}$, forming the $T_{1}$ state $\mathbf{A B}$ and the $S_{0}$ state $B P$. $\mathbf{A B}$ 
can be grafted onto the PE chain, which consists of two fragments, 4-(2,5-dioxo-2,5-dihyro-pyrrol-1-yl)- benzoic acid (A fragment) and 2,4-dihydroxybenzophenone (B fragment) [18]. We calculated key structural parameters of the reactions between the molecule $\mathbf{A B}$ and the model compound Pe are listed in Table 2. At the same time, the relevant data of the two fragments $\mathbf{A}$ and $\mathbf{B}$ are also listed in Table 2. The $E_{\mathrm{g}}, \operatorname{IP}(a) \mathrm{s}$, and $\mathrm{EA}(a)$ s of studied molecules calculated are listed in Table 3, and their NBO calculation results are listed in Table 4.

\subsection{Stationary point geometries and NBO Charge Population}

The optimized structures of the reactants, transition states and products on $\mathrm{S}_{0}$ or $\mathrm{T}_{1}$ states for nine channels were obtained. The standard coordination of the TSs for every channel is given in the supporting information. The schematic diagram of reaction progress of the studied nine channels is shown in Fig. 2.

Four sites on the $\mathbf{A B}$ molecule can undergo $\mathrm{H}$ addition reactions with $\mathrm{Pe}$, one is electrophilic addition reaction of the 4-position hydrogen in $\mathrm{Pe}$ to $\mathrm{C}$ of $\mathrm{C}=\mathrm{C}$ group and the other three are electrophilic addition reaction of the 4-position hydrogen in Pe to $\mathrm{O}$ of $\mathrm{C}=\mathrm{O}$ groups (the three sites are carbonyl in amide, ester carbonyl and ketone carbonyl, respectively). The natural charge density (-0.14) on site 1 in AB molecule given in Table 4 is lower than that of others.

The maleimide structure in Fig. 1 , the $\mathrm{N}$ atom and the carbonyl group $\mathrm{C}=\mathrm{O}$ form $\mathrm{p}-\pi$ conjugate, and $\mathrm{N}$ atom exhibits a strong electron donating conjugation effect, which increases the electron cloud density on the carbonyl group $\mathrm{C}=\mathrm{O}$, and the $\pi$ electron cloud shifts from $\mathrm{C}$ to $\mathrm{O}$, which increases the amount of negative charge on $\mathrm{O}$ of $\mathrm{C}=\mathrm{O}$ (site 2). As a result, the density of the electron cloud on the $\mathrm{C}=\mathrm{C}$ double bond decreases significantly. The electrophilic addition reaction of $\mathrm{C}=\mathrm{C}$ group in the $\mathbf{A B}$ molecule would be easier than that of $\mathrm{C}=\mathrm{O}$ groups. For the three addition channels on 
the $\mathrm{O}$ of $\mathrm{C}=\mathrm{O}$ groups in $\mathbf{A B}$ molecule, the natural charge density on site $2(-0.33)>$ site $4(-0.25)>$ site $3(-0.17)$. As a result, site 2 shows higher reactivity, the reaction potential barrier heights of $\mathbf{A B}$ on site 2 would be lower than those of the other two reaction site 3 and 4.

The calculated imaginary frequencies of nine transition states, the optimized bond lengths for breaking and forming bonds, and the corresponding chemical reaction equations are listed in Table 2. The normal mode analysis confirms that all transition states present a single imaginary frequency which corresponds to the stretching mode of coupling fracture and bond formation. In TSA-1 and TAB-1 structures, it can be seen that the breaking bonds $\mathrm{C}-\mathrm{H}$ increase by $18.27 \%$ and $18.09 \%$ compared with the equilibrium bond length in $\mathrm{Pe}$; the forming bonds $\mathrm{C}-\mathrm{H}$ stretch by $32.18 \%$ and $32.36 \%$ over the equilibrium bond lengths in isolated $\mathbf{A}$ and $\mathbf{A B}$, respectively. The elongation of the breaking bond is smaller than that of the corresponding forming bond, in the case of the three electrophilic addition reaction channels of TSB, TSAB-2 and TSA-2, similar features can be drawn, which indicates that the above-mentioned electrophilic addition reactions are all reaction-like, i.e., the five reaction channels will proceed via "early" transition states. It is consistent with Hammond's postulate [28], for an exothermic reaction.

\subsection{Frontier MOs and Energetics}

Table 3 lists the adiabatic IP (a), EA ( $a$ ) and the corresponding experimental data [29], as well as the calculated HOMO-LUMO gap $\left(E_{g}\right)$, the value of BP for reference. Compared with Pe, the other molecules in Table 3 all have $\pi$ bonds. $\pi$ bond has higher HOMO and lower LUMO compared with $\sigma$ bond, so the $E_{g}$ value is relatively lower. Moreover, as the conjugated system increases, the gap between the HOMO and the LUMO keeps narrowing. Therefore, the order of $E_{g}$ values is: $\mathbf{A B}<\mathbf{A}<\mathbf{B}<$ MAM $<$ 
$\mathrm{BP}<\mathrm{Aa}<\mathrm{Pe}$, and $\mathbf{A B}$ has the lowest $E_{g}$ value.

The $\sigma$ electrons are in the $s p^{\mathrm{n}}$ hybrid orbits, which are close to the nucleus. The $\sigma$ electrons can not dissociate easily, as they are firmly attracted by the nucleus. While the $\pi$ electrons are in the $p$ orbitals, which are far from the nucleus, so they are easier to dissociate than the $\sigma$ electrons. In a conjugated system, the degree of delocalization of $\pi$ electrons will increase with the enlarging of the conjugated system, and the degree of being bounded by the nucleus will be lower, so it is easier for $\pi$ electrons to dissociate from the system. It is reported that compounds containing conjugated aromatic structure are suitable to act as voltage stabilizers $[16,17]$. The IP values in Table 3 of BP, Aa, AB, A and $\mathbf{B}$ are all smaller than Pe, while the IP value of MAM is the highest. The analysis shows that the proportion of heteroatoms in MAM's conjugated chain is $3 / 7(4 \mathrm{C}$ atoms, $1 \mathrm{~N}$ atom and $2 \mathrm{O}$ atoms), which is higher than that of the other conjugated molecules. Compared with $\mathrm{C}$ atoms, heteroatoms have the greater electronegativity, so the electrons in MAM are not easy to emit. At the same time, the greater the proportion of electronegative atoms in the molecule is, the easier it is to accept the hot electrons. MAM contains relatively more heteroatoms, so its EA value $(1.35 \mathrm{eV})$ is relatively large, much larger than Pe. It is reported that MAM can be used as space charge inhibitor $[14,15]$. On the other hand, our researches show that when the conjugated system in the molecule gets larger, its accepting hot electrons' ability gets higher as while, and it is much easier for the larger conjugated system to disperse the accepted hot electrons, so the EA value becomes higher, this regularity can be seen in Table 3 also. In consideration of the above two factors, the EA value of $\mathbf{A B}$ is the largest.

As a voltage stabilizer, it needs to have an excellent ability to receive hot electrons, AB molecule has it, at the same time, the imine structure in $\mathbf{A B}$ has the capability of 
space charge suppression. Therefore, it is ideal to select $\mathbf{A B}$ molecule as a multi-functional additive to improve the electric breakdown strength and inhibit the generation of space charge. We focus on the potential energy surface of the reaction between $\mathbf{A B}$ molecule and Pe in the following study.

The reaction energy barrier $\left(\Delta G^{\neq}\right)$and the reaction Gibbs free energy $\left(\Delta G^{0}\right)$ for the nine reaction channels are also listed in Table 2. AB can be sensitized by photo-initiator BP mentioned above. It can be seen that $\mathbf{A B}, \mathbf{A}$ and $\mathbf{B}$ can be grafted to the Pe chain by UV radiation, moreover, $\mathbf{A B}$ can be grafted to the Pe chain through four sites. From the data in Table 2, we can also discover that the order of reaction potential barrier $\left(\Delta \mathrm{G}^{\neq}\right)$of four sites in $\mathbf{A B}$ is $\Delta \mathrm{G}^{\neq}{ }_{\text {site1 }}(0.89 \mathrm{eV})<\Delta \mathrm{G}^{\neq}{ }_{\text {site2 }}(1.24 \mathrm{eV})$ $<\Delta \mathrm{G}^{\neq}{ }_{\text {site4 }}(1.96 \mathrm{eV})<\Delta \mathrm{G}^{\neq}{ }_{\text {site3 }}(2.05 \mathrm{eV})$. As for the reaction on site 1 , it has the lowest reaction potential barrier among the four reaction channels.

For the three electrophilic addition reactions of the 4-position hydrogen in Pe to $\mathrm{C}$ of $\mathrm{C}=\mathrm{O}$ groups (carbonyl in amide, ester carbonyl and ketone carbonyl), the reaction potential barrier on site 3 of $\mathbf{A B}$ is $2.05 \mathrm{eV}$, which is the highest among the four reaction sites. Site 2 has the lowest reaction potential barrier $(1.24 \mathrm{eV})$ and the lowest Gibbs free energy $\left(\Delta \mathrm{G}^{0}=-0.01 \mathrm{eV}\right)$. The reaction channel of site 2 is more advantageous than other channels in thermodynamics and kinetics. In Table 2, we can see that the reaction potential barrier of the grafting of $\mathbf{A B}$ on site 3 is higher than that on site 2 and site 4 , this is consistent with the results of natural charge population discussed above (see Table 4). It can be deduced that with the increasing of charge density of the $\mathrm{C}=\mathrm{O}$ double bond, the reaction potential barrier of electrophilic addition reaction decreases. In other words, when the charge density of the $\mathrm{C}=\mathrm{O}$ double bond in the molecule decreases, the electrophilic hydrogen addition reaction will become more and more difficult. 
Compare the addition reaction on $\mathrm{C}$ of $\mathrm{C}=\mathrm{C}$ group with $\mathrm{O}$ of $\mathrm{C}=\mathrm{O}$ group in $\mathbf{A B}$, it can be seen from Table 2 that for the electrophilic addition reaction at 4-position hydrogen in $\mathrm{Pe}$ with $\mathrm{O}$ of $\mathrm{C}=\mathrm{O}$ group, a larger conjugated system has not been formed.

Because the conjugated structure of the diimide<smiles>[R]N(C(C)=O)C(C)=O</smiles>

is destroyed, resulting in a<smiles>[R]N1C(=O)C=C[C@H]1O</smiles>

cross conjugated system

. The cross conjugated system is weaker than that of the diimide conjugated system, and the corresponding cross conjugated system reaction activity becomes weaker. While for the electrophilic addition reaction of the 4-position hydrogen in $\mathrm{Pe}$ to $\mathrm{C}$ of $\mathrm{C}=\mathrm{C}$ group, it is just on the opposite. The

\section{conjugated structure of diimide}<smiles>[R]N(C(C)=O)C(C)=O</smiles>

is not broken and the reactivity is enhanced. Thus, $\Delta \mathrm{G}^{\neq}$(site 1) $(0.89 \mathrm{eV})<\Delta \mathrm{G}^{\neq}$(site 2$)(1.24 \mathrm{eV})$. The value of NBO in Table 4 exactly illustrates the problem. In experimental study $\mathbf{A B}$ can be grafted onto the PE chain [18]. According to our computed results, the electrophilic addition reaction of the 4-position hydrogen in $\mathrm{Pe}$ to $\mathrm{C}$ of $\mathrm{C}=\mathrm{C}$ group is the dominant reaction channel. AB can be used as a potential multi-functional additive of XLPE insulation material. In addition, as aryl cation in $\mathbf{A B}$ molecule possesses strong ability of $\pi$-electron delocalization than that of alkyl cation PE, aromatic molecule $\mathbf{A B}$ is chosen as an additive added in XLPE composite material, which can restore alkyl cation radical from transforming the alkyl cation radical to relatively stable aryl cation radical.

\section{Conclusion}

The multiple-channel addition reactions mechanism of hydrogen in polyethylene to four sites on $\mathbf{A B}$ molecule has been investigated. The electrophilic addition reaction 
of the 4-position hydrogen in $\mathrm{Pe}$ to $\mathrm{C}$ of $\mathrm{C}=\mathrm{C}$ group is more likely to occur than that of the 4-position hydrogen in $\mathrm{Pe}$ to $\mathrm{O}$ of $\mathrm{C}=\mathrm{O}$ groups. As a multi-functional additive, AB molecule can be grafted onto the PE chain by UV radiation to avoid migration. As a UV absorber, $\mathbf{A B}$ molecule can play roles as a voltage stabilizer and space electron inhibitor, improve the electronic breakdown strength of PE insulating materials, and inhibit the generation and accumulation of space charges. The use of multi-functional AB molecule in the material system will reduce the amount of additives and the introduction of chemical impurities, and improve the electronic conductivity of insulating materials.

\section{Acknowledgements}

This work is supported by the National Natural Science Foundation of China (51337002) and Key Project of the Joint Fund for Regional Innovation and Development of National Natural Science Foundation of China (U20A2030).

\section{Declaration}

Availability of data and material The standard coordination of the TSs for every channel is given in the supporting information.

Code availability The study was carried out on the basis of Gaussian 09, Revision A.01.

Authors' contributions We declare that this work was done by the authors named in this article, and all liabilities pertaining to claims relating to the content of this article will be borne by the authors. In addition, a declaration of the role of each author mentioned as follows: Prof. Hui Zhang carried out the geometry optimizations, participated in data analysis, and drafted the manuscript; Dr. Chi Deng carried out the calculation of stationary points and frequency analysis; Dr. Xia Du carried out the 
calculation of charger density and the statistical analysis, collected field data; Prof.

247 Yan Shang participated in the analysis of the results; Prof. Hong Zhao, Xuan Wang 248 and Baozhong Han designed the study; Prof. Zesheng Li helped perform the analysis

249 with constructive discussions. All authors read and approved the final manuscript.

250 Conflicts of interest The authors declare no competing interests. 


\section{References}

[1] Orton H (2015) Power cable technology review[J]. High Voltage Engineering. 41:1057-1067

[2] Montanari GC, Laurent C, Teyssedre G, Campus A, Nilsson UH (2005) From LDPE to XLPE: Investigating the change of electrical properties. Part I. space charge, conduction and lifetime[J]. IEEE Trans Dielectr Electr Insul 12: 438-446. https://doi:10.1109/TDEI.2005.1453448

[3] Mazzanti G, Montanari GC, Dissado LA (2005) Electrical aging and life models: the role of space charge[J]. IEEE Trans Dielectr Electr Insul 12: 876-890. https://doi:10.1109/TDEI.2005.1522183

[4] Montanari GC, Mazzanti G, Palmieri F, Motori A, Perego G, Serra S (2001) Space-charge trapping and conduction in LDPE, HDPE and XLPE[J]. J Phys D 34: 2902-2911. https://doi:10.1088/0022-3727/34/18/325

[5] Zhang H, Shang Y, Zhao H, Han BZ, Li ZS (2013) Mechanisms on electrical breakdown strength increment of polyethylene by acetophenone and its analogues addition:a theoretical study[J]. J Mol Model 19: 4477-4485. https://doi:10.1007/s00894-013-1946-1

[6] Zhang H, Shang Y, Li MX, Zhao H, Wang X, Han BZ (2015) Theoretical study on the radical reaction mechanism in the cross-linking process of polyethylene[J]. RSC Adv 5: 90343-90353. https://doi:10.1039/c5ra16339k

[7] Zhang H, Shang Y, Wang X, Zhao H, Han BZ, Li ZS (2013) Mechanisms on electrical breakdown strength increment of polyethylene by aromatic carbonyl compounds addition: a theoretical study[J]. J Mol Model 19: 5429-5438. https://doi:10.1007/s00894-013-2028-0

[8] Yamano Y, Endoh H (1998) Increase in breakdown strength of PE film by 
additives of azocompounds[J]. IEEE Trans Dielectr Electr Insul 5: 270-275.

[9] Yamano Y (2006) Roles of polycyclic compounds in increasing breakdown strength of LDPE film[J]. IEEE Trans Dielectr Electr Insul 13: 773-781. https://doi:10.1109/TDEI.2006.1667735

[10] Yamano Y, Iizuka M (2009) Suppression of electrical tree initiation in LDPE by additives of polycyclic compound[J]. IEEE Trans Dielectr Electr Insul 16: 189-198. https://doi:10.1109/TDEI.2009.4784567

[11] Jarvid M, Johansson A, Englund V, Gubanski S, Andersson MR (2012) Electrical treeing Inhibition by Voltage Stabilizers, Annual Report Conference on Electrical Insulation and Dielectric Phenomena, 605-608

[12] Lee SH, Park JK, Han JH, Suh KS (1997) Space charge behavior in maleic anhydride grafted polyethylene/ethylene-vinyl-acetate copolymer laminates[J]. J Phys D Appl Phys 30:1. https://doi:10.1088/0022-3727/30/1/001

[13] Lee SH, Park JK, Han JH, Suh KS (1995) Space charge and electrical conduction in maleic anhydride-grafted polyethylene[J]. IEEE Trans Dielectr Electr Insul 2: 1132-1139. https://doi:10.1109/TDEI.1995.8881931

[14] Zhang H, Shang Y, Zhao H, Li CY, Wang X, Han BZ, Li ZS (2018) Theoretical study on the grafting reaction of maleimide to polyethylene in the UV radiation $\begin{array}{lllll}\text { cross-linking } & \text { process[J]. } & \text { Polymers } & 10: & 1044 .\end{array}$ https://doi:10.3390/polym10091044

[15] Wang Y, Zhang H, Zhao H, An T, Du X, Lu Y, Chen ZG (2019) Theoretical study on the grafting reaction of maleimide and its derivatives to polyethylene in the UV radiation cross-linking process[J]. Struc Chem 30: 1033-1039. https://doi:10.1007/s11224-018-1250-X

[16] Zhang H, Shang Y, Zhao H, Wang X, Han BZ, Li ZS (2016) Theoretical study on 
the tailored side-chain architecture of benzil-like voltage stabilizers for enhanced dielectric strength of cross-linked polyethylene[J]. RSC Adv 6: 11618. https://doi:10.1039/c5ra23718a

[17] Zhang H, Zhao H, Wang X, Shang Y, Han BZ, Li ZS (2014) Theoretical study on the mechanisms of polyethylene electrical breakdown strength increment by the addition of voltage stabilizers. J Mol Model 20: 2211. https://doi:10.1007/s00894-014-2211-y

[18] Na HS, Kim TH (2014) Grafting of maleimide containing 2-hydroxy-benzophenone onto polyethylene: reaction conditions and photo-stabilization effects. Macromol Res 22: 958-962. https://doi:10.1007/s13233-014-2133-7

[19] Parr RG, Yang W (1989) Density-Functional Theory of Atoms and Molecules, Oxford University Press, New York, NY, USA

[20] Truong TN, Duncan WT, Bell RL (1996) Chemical Applications of Density Functional Theory, vol. 85, American Chemical Society, Washington, DC, USA, ISBN 0-8412-3403-5

[21] Lee C, Yang W, Parr RG (1988) Development of the Colle-Salvetti conelation energy formula into a functional of the electron density. Phys Rev B 37: 785-789, https://doi.org/10.1103/PhysRevB.37.785

[22] Miehlich B, Savin A, Stoll H, Preuss H (1989) Results obtained with the correlation energy density functionals of becke and Lee, Yang and Parr. Chem Phys Lett 157: 200-206. https://doi.org/10.1016/0009-2614(89)87234-3

[23] Becke AD (1993) Density-functional thermochemistry. III. The role of exact exchange. J Chem Phys 98: 5648-5652. https://doi.org/10.1063/1.464913

[24] Zangwill A, Soven P (1980) Density-functional approach to local-field effects 
infinite systems-photoabsorption in the rare-gases. Phys Rev A 21:1561-1572. https://doi.org/10.1103/PhysRevA.21.1561

[25] Levine ZH, Soven P (1984) Time-dependent local-density theory of dielectric effects in small molecules. Phys Rev A 29: 625-635. https://doi.org/10.1103/PhysRevA.29.625

[26] Reed AE, Weinstock RB, Weinhold F (1985) Natural population analysis. J Chem Phys 83: 735-746. https://doi.org/10.1063/1.449486

[27] Frisch J, Trucks GW, Schlegel HB, Scuseria GE, Robb MA, Cheeseman JR, Scalmani G, Barone V, Mennucci B, Petersson GA, et al. (2010) Gaussian 09 Revision B.01, Gaussian Inc., Wallingford CT

[28] Hammond GS (1955) J Am Chem Soc 77: 334.

[29] Lias SG, Levin RD, Kafafi SA, Bartmess JE, NIST ChemistryWebBook, NIST standard reference database number 69. https://webbook.nist.gov/chemistry/ 


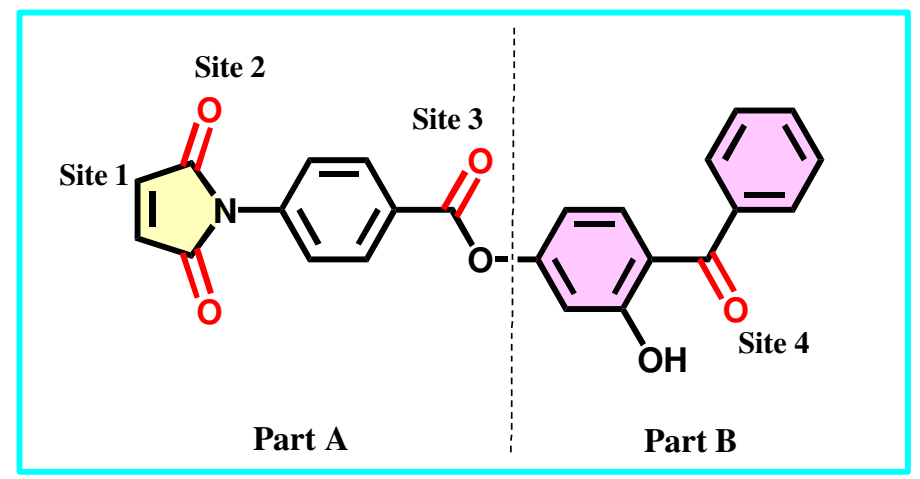

Figure 1 Schematic diagram of molecular structure of AB 


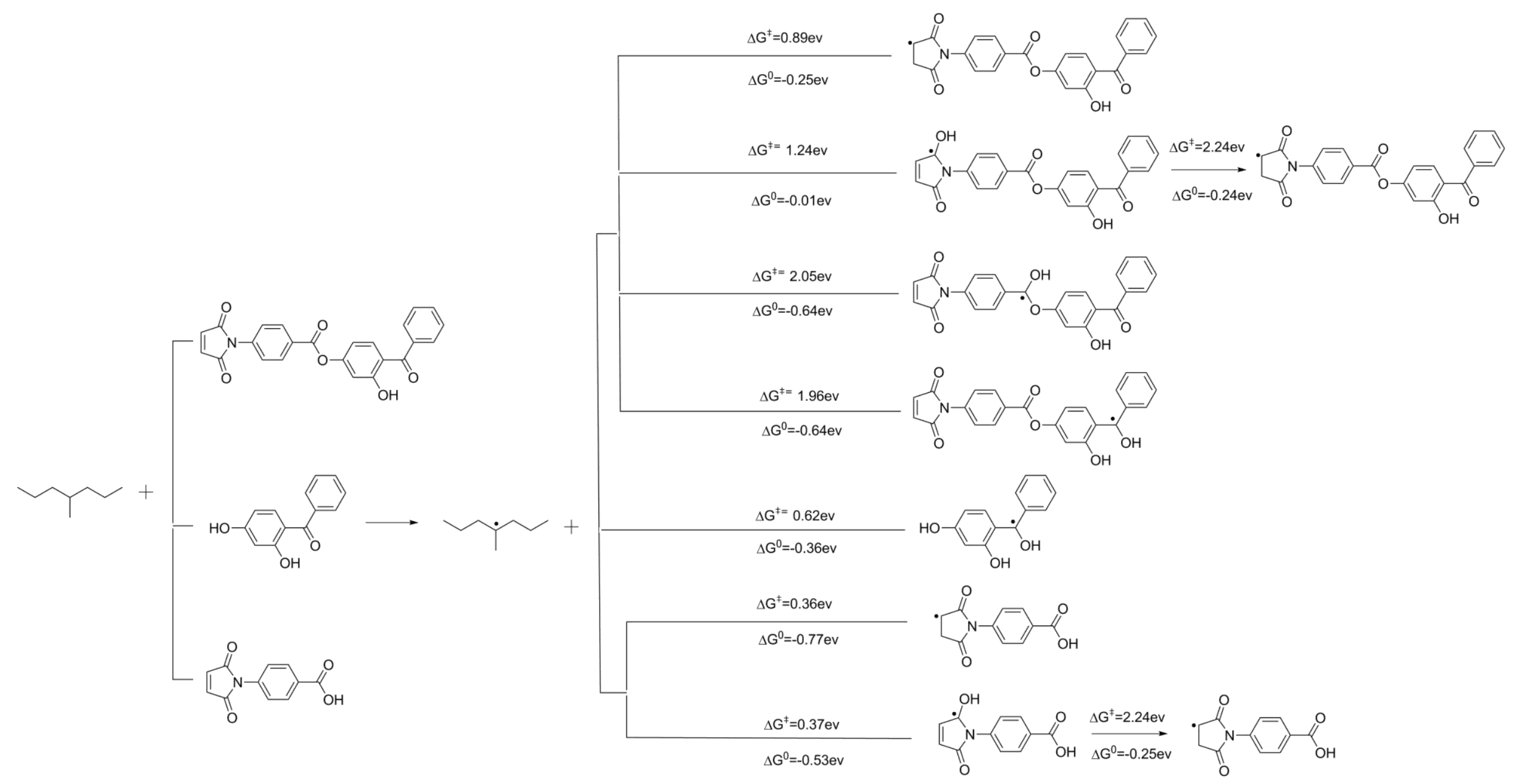

Figure 2 The schematic diagram of reaction progress of the studied nine channels 
Table 1 The molecular name, the molecular formula, and corresponding abbreviation (ab.) of the studied molecules.

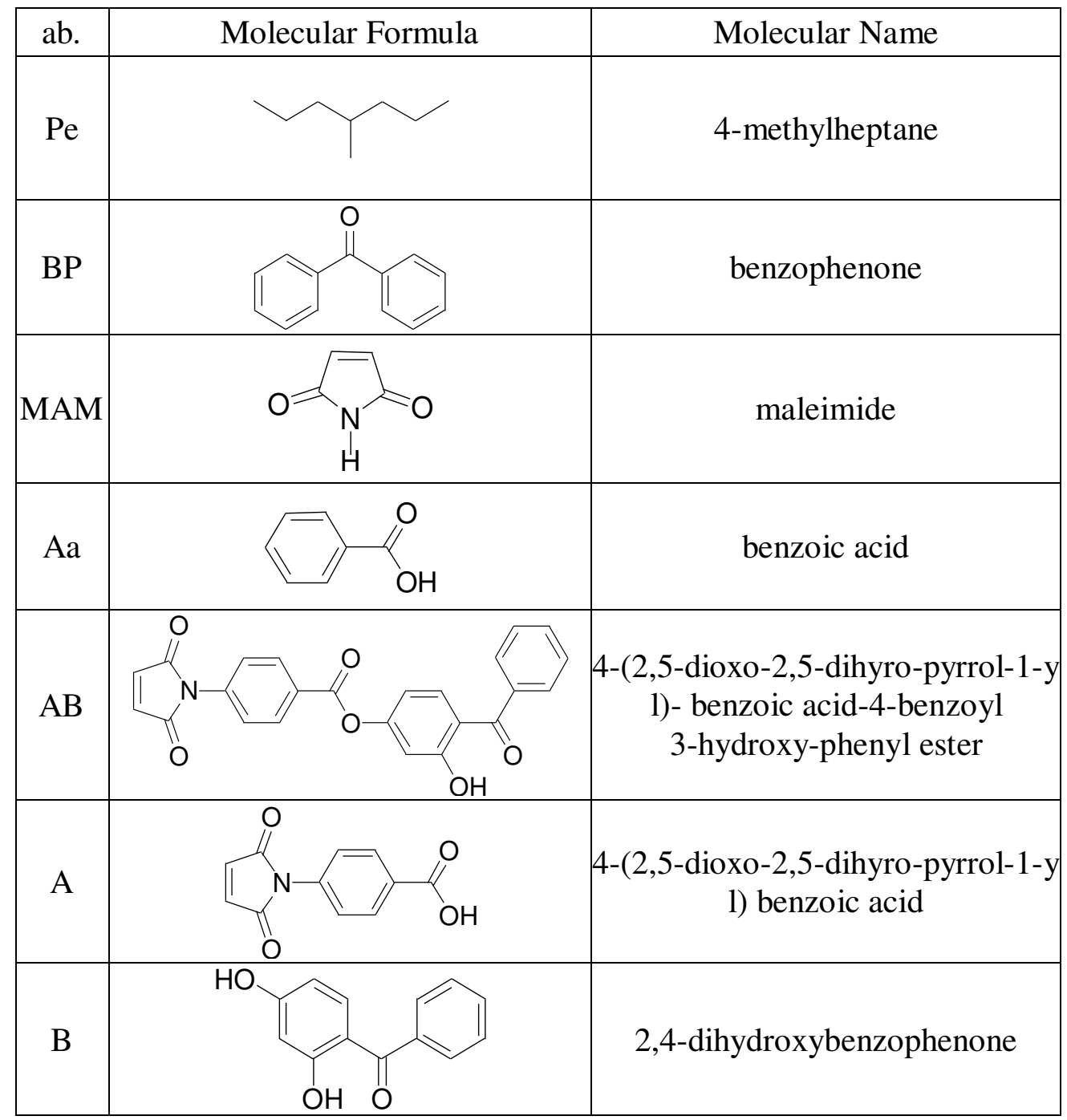


Table 2 Optimized bond lengths of breaking/forming bonds for transition state, reactants and products (in angstrom), together with the calculated breaking/forming bond frequencies (in $\mathrm{cm}^{-1}$ ), the reaction energy barrier $\left(\Delta \mathrm{G}^{\neq}\right.$) and reaction Gibbs free energies $\Delta \mathrm{G}^{0}$ (in $\mathrm{eV}$ ), as well as the abbreviation of transition state (ab.).

\begin{tabular}{|c|c|c|c|c|c|c|c|}
\hline reaction equation & reactant & $b / f$ & product & freq. & $\Delta \mathrm{G}^{\neq}$ & $\Delta \mathrm{G}^{0}$ & ab. \\
\hline & 1.100 & $1.228 / 1.395$ & 0.964 & $835 i$ & 0.60 & -0.46 & TSBP \\
\hline & 1.100 & $1.239 / 1.375$ & 0.965 & $1156 i$ & 0.62 & -0.36 & TSB \\
\hline & 1.100 & $1.301 / 1.450$ & 1.097 & $1198 i$ & 0.36 & -0.77 & TSA-1 \\
\hline & 1.100 & $1.192 / 1.496$ & 0.964 & $334 i$ & 0.37 & -0.53 & TSA-2 \\
\hline & 0.964 & $1.382 / 1.505$ & 1.097 & $2010 i$ & 2.24 & -0.25 & TSA-3 \\
\hline & 1.100 & $1.299 / 1.452$ & 1.097 & $1182 i$ & 0.89 & -0.25 & TSAB-1 \\
\hline
\end{tabular}




\begin{tabular}{|l|l|l|l|l|l|l|l|l|l|l|}
\hline & TSAB-2 \\
\hline
\end{tabular}


Table 3 The $E_{\mathrm{g}}$, IPs, and EAs of studied molecules calculated as well as the corresponding experimental data in the bracket (in $\mathrm{eV}$ ).

\begin{tabular}{|c|c|c|c|c|}
\hline ab. & molecular formula & $E_{\mathrm{g}}$ & $\operatorname{IP}(a)$ & $\mathrm{EA}(a)$ \\
\hline $\mathrm{Pe}$ & & 8.38 & 9.41 & -1.09 \\
\hline BP & & 4.90 & $8.64(9.05)$ & $0.73(0.69 \pm 0.05)$ \\
\hline MAM & & 4.78 & 10.22 & 1.35 \\
\hline $\mathrm{Aa}$ & & 5.65 & $9.30(9.30)$ & 0.23 \\
\hline $\mathrm{AB}$ & & 3.28 & 7.91 & 2.00 \\
\hline A & & 3.92 & 8.55 & 1.86 \\
\hline B & & 4.60 & 7.80 & 0.46 \\
\hline
\end{tabular}

Table 4 Natural charges population analysis of four sites on $\mathrm{T}_{1}$ state of $\mathbf{A B}$ molecule.

\begin{tabular}{|c|c|c|c|c|}
\hline & \multicolumn{4}{|c|}{ Natural Charges Population } \\
\hline
\end{tabular}


Figures

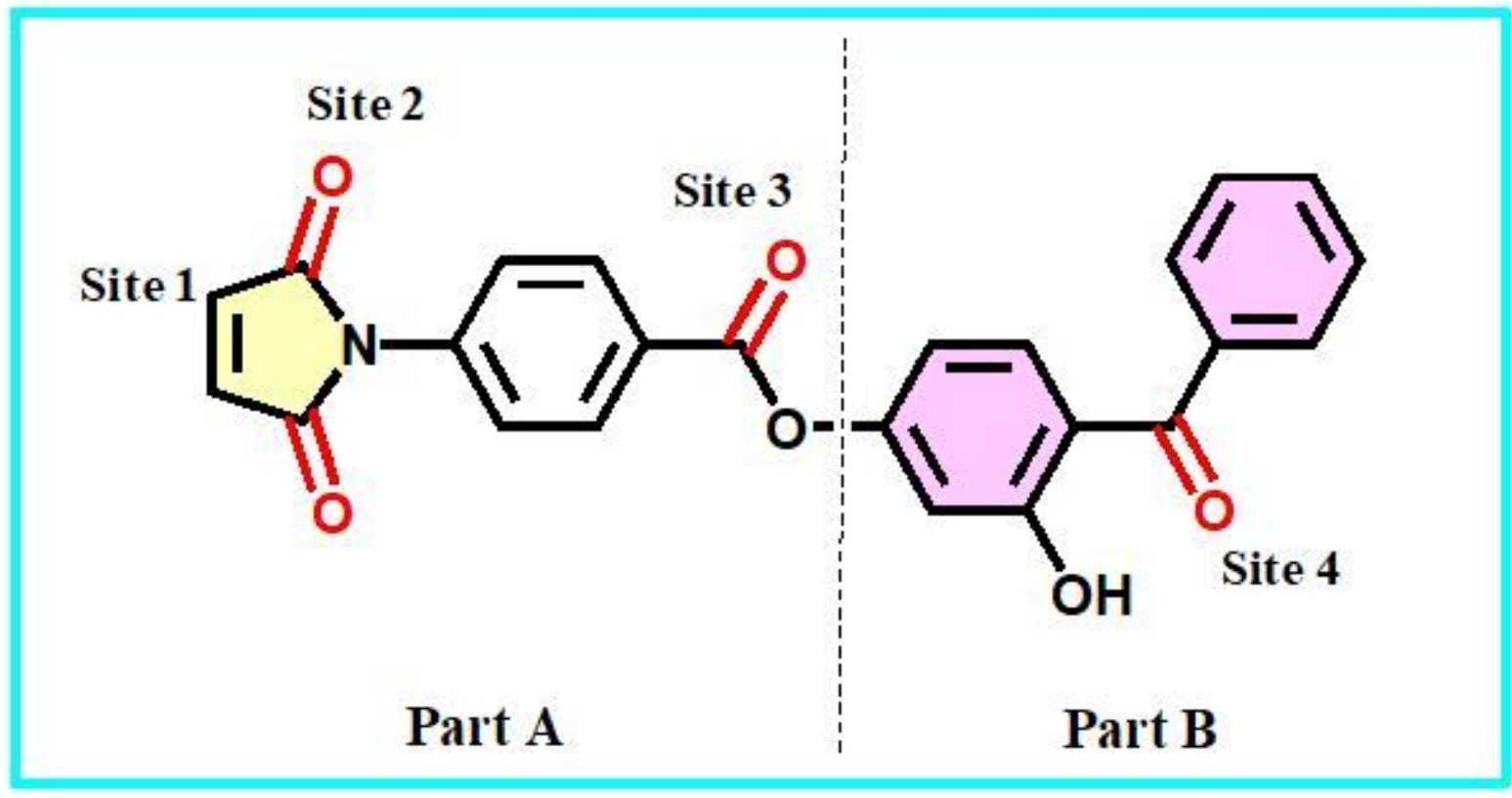

Figure 1

Schematic diagram of molecular structure of $A B$
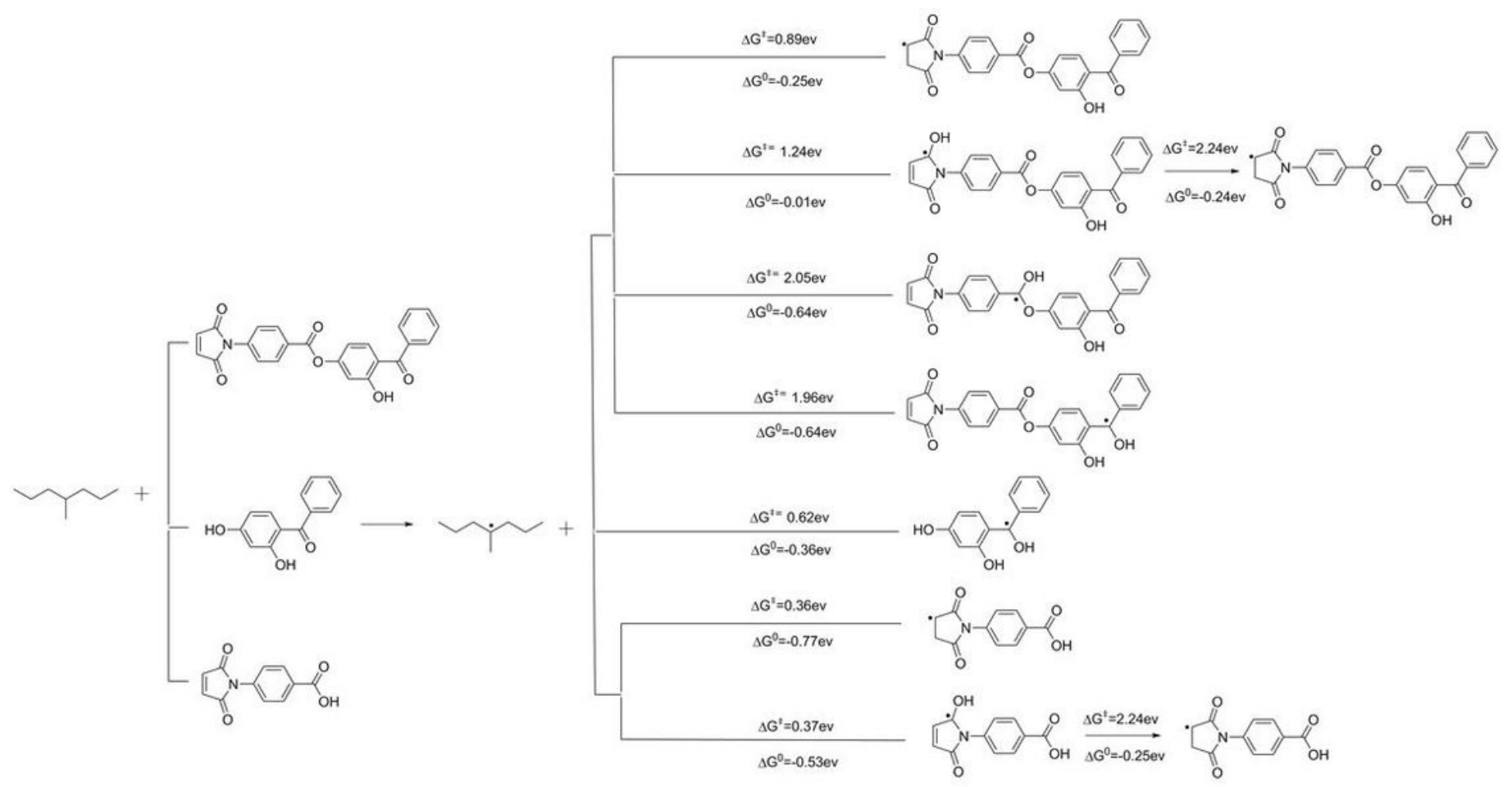
Figure 2

The schematic diagram of reaction progress of the studied nine channels

\section{Supplementary Files}

This is a list of supplementary files associated with this preprint. Click to download.

- graphicalabstract.jpg

- supportinginformation.doc 